\title{
Characterization of proteins secreted by pancreatic cancer cells with anticancer drug treatment in vitro
}

\author{
TAKANOBU TAKATA $^{1}$, YASUHITO ISHIGAKI ${ }^{1}$, TAKEO SHIMASAKI $^{1,2}$, HIDEYUKI TSUCHIDA $^{3}$, \\ YOSHIHARU MOTOO ${ }^{1,2}$, AKIO HAYASHI ${ }^{4}$ and NAOHISA TOMOSUGI ${ }^{1,5}$ \\ ${ }^{1}$ Medical Research Institute, Kanazawa Medical University, Uchinada; ${ }^{2}$ Department of Medical Oncology, \\ Kanazawa Medical University; ${ }^{3}$ Department of Advanced Medicine, Kanazawa Medical University; \\ ${ }^{4}$ Agilent Technologies Japan, Ltd., Takakura, Hachioji 192-8510; ${ }^{5}$ Department of Nephrology, \\ Kanazawa Medical University, Uchinada, Japan
}

Received April 26, 2012; Accepted July 23, 2012

DOI: 10.3892/or.2012.2020

\begin{abstract}
Pancreatic cancer is one of the most lethal cancers, with an incidence equaling mortality. It is a heterogeneous group of neoplasms in which pancreatic ductal adenocarcinoma is most common. Pancreatic cancer cannot be cured even if detected early. When treatment is initiated, a suitable method of administration of anticancer drugs must be chosen. Anticancer drugs kill tumor cells. However, side effects including initiation are problematic in anticancer drug therapy. Improved methods for the diagnosis of side effects of pancreatic cancer by using sensitive and specific tumor markers are highly desirable. Therefore, efficient strategies for biomarker discovery are urgently needed. Here, we present an approach based on direct experimental access to proteins released by PANC-1 human pancreatic cancer cells in vitro. A two-dimensional (2-D) map and catalog of this subproteome, herein termed the secretome, were established comprising more than 1,000 proteins observed by ' 2 -D difference in-gel electrophoresis analysis using cyanine dye'. We investigated 22 spots that were 1.20 -fold upregulated and 31 spots that were 0.66-fold downregulated by gemcitabine chloride treatment. Proteins in these spots were identified by nano-high-performance liquid chromatography electrospray ionization time of flight mass spectrometry/mass spectrometry. Most secretome constituents were nominally cellular proteins. By mass spectrometry screening, 14-3-3 protein sigma (14-3-3 $\sigma$ ), protein S100-A8, protein S100-A9, galectin-7, lactotransferrin (lactoferrin, LF) precursor, serotransferrin (transferrin) precursor, and vitamin D binding protein precursor were identified.
\end{abstract}

Correspondence to: Dr Naohisa Tomosugi, Division of Aging Research, Department of Advanced Medicine, Medical Research Institute, Kanazawa Medical University, 1-1 Daigaku, Uchinada, Ishikawa 920-0293, Japan

E-mail: tomosugi@kanazawa-med.ac.jp

Key words: Panc-1, gemcitabin, secretome, 14-3-3 protein sigma, lactoferrin
Western blotting confirmed the presence of 14-3-3 $\sigma$ and LF. We found that upregulation of 14-3-3 $\sigma$ was associated with apoptosis, and downregulation of LF was found to suppress tumorigenesis.

\section{Introduction}

Pancreatic cancer is one of the most lethal cancers, with an incidence equaling mortality. It is a heterogeneous group of neoplasmis in which pancreatic ductal adenocarcinoma is the most common form (1).

Pancreatic cancers cannot be cured even if detected early. It is one of the most aggressive and lethal cancers worldwide and is highly resistant to chemotherapy. Over the past decade, gemcitabine (2',2'-difluorodeoxycytidine, GEM) has been the first-line treatment for advanced pancreatic cancer, but it offers only modest benefit due to pre-existing or acquired chemoresistance (2). Furthermore, recent clinical studies indicate that only $20 \%$ of patients with advanced pancreatic cancer responsed to GEM (3). Combining GEM with other chemotherapeutic agents improves the therapeutic outcome, but results to date remain meager. Therefore, novel approaches that significantly enhance the effects of GEM or overcome chemoresistance to the drug are needed to effectively combat pancreatic cancers.

Proteins that are released by human tumor cells in vivo and reach the circulation are strongly outweighed by all the normal blood constituents. Thus, seeking an alternative source for the discovery of biomarkers for assessing 'response to GEM', we have developed a protocol that provides direct experimental access to a promising subproteome of proteins released by human pancreatic cancer cells in vitro. Release of proteins from tumor cells in vivo and in vitro is due to diverse mechanisms and is not confined to classical secretion, but for the sake of simplicity we follow previous publications and refer to similar subproteomes subproteomes. Classical secretion is the most obvious mode of protein release and is expected to be relevant for proteins such as extracellular matrix molecules. Exosomes are membrane-coated vesicles derived from multivesicular bodies in the late endosomal compartment. They were first detected as products of pancreatic cells and are 
regarded as important devices for intercellular communication in the regulation of responses to GEM. We have therefore established an empirical approach for the isolation, identification and characterization of the subset of proteins released by pancreatic carcinoma cells treated with GEM in vitro. With this aim, we chose the PNAC-1 pancreas carcinoma cell line as a model. Proteins were harvested from conditioned media, concentrated and resolved using two-dimensional difference in-gel electrophoresis (2D-DIGE) and labeled with cyanine (Cy) dye.

Differential analysis showed that, 53 spots in the gel revealed marked differences in protein expression. Twenty-two spots were upregulated $>1$.2-fold in response to GEM treatment and 31 spots were downregulated $<0.66$-fold $(\mathrm{P}<0.01)$. These spots were picked from other gels which could be assigned to distinct spots in the master gel. Approximately 50 proteins were identified from these spots by nano-high-performance liquid chromatography-electrospray ionization time of flight mass spectrometry/mass spectrometry (HPLC-ESI-MS/MS). Most of them were nominally cellular proteins. The identified proteins included the secreted proteins 14-3-3 protein sigma (14-3-3 б), protein S100-A8, protein S100-A9, galectin-7, lactotransferrin (lactoferrin, LF) precursor, serotransferrin (transferrin, TF) precursor, and vitamin D binding protein precursor. Western blot analysis confirmed the upregulation of 14-3-3 $\sigma$, which is associated with apoptosis, and the dowregulation of LF was found to suppress tumorigenesis.

\section{Materials and methods}

Chemicals and reagents. Cy dye DIGE fluors (Cy2, Cy3 and Cy5 for minimal labeling), IPG buffer ( $\mathrm{pH} 3.0-10.0)$, Immobile DryStrip (24 cm, pH 3.0-10.0), sodium dodecyl sulfate (SDS), $N, N, N^{\prime}, N^{\prime}$-tetramethylethylenediamine, bind-silane, urea and thiourea were obtained from GE Healthcare (Tokyo, Japan). $N, N$-dimethyformamide (DMF) was purchased from Sigma-Aldrich (Tokyo, Japan). 2-amino-2-hydroxymethyl1,3-propanediol (Tris-(hydroxymethyl)-aminomethane), potassium hexacyanoferrate (III), sodium thiosulfate, acetonitrile, acetone, dithiothreitol, iodoacetamide and tetrafuloroacetic acid were obtained from Wako Pure Chemical Industries, Ltd. (Osaka, Japan).

SYPRO Ruby was purchased from Invitrogen (Tokyo, Japan). GEM chloride was obtained from Eli Lilly Japan K.K. (Kobe, Japan). The Bradford protein assay kit was purchased from Bio-Rad Laboratories (Tokyo, Japan). Centriplus YM-3 was obtained from Millipore (Bedford, MA, USA).

Cell culture. The human pancreatic carcinoma cell line PANC-1 was obtained from RIKEN BioResource Center Cell Bank (Japan). PANC-1 cells were maintained in Dulbecco's modified Eagle's medium (D-MEM) supplemented with $10 \%$ fetal calf serum (FCS), $2 \mathrm{mM}$ glutamine, $100 \mathrm{U} / \mathrm{ml}$ penicillin and $100 \mathrm{mg} / \mathrm{ml}$ streptomycin. For secretome preparation, cells were cultured at $1.5 \times 10^{6} \mathrm{cell} / \mathrm{ml}$ in D-MEM until of $70-80 \%$ confluence (4).

Treatment with GEM. GEM at $10 \mu \mathrm{g} / \mathrm{ml}$ was added to the cells. The cells were incubated for $24 \mathrm{~h}$, then washed five times with phosphate-buffer saline (PBS) and incubated in serum-free medium (Sigma, St. Louis, MO, USA) for another $48 \mathrm{~h}$. This protocol did not measurably influence the apoptosis rate compared with standard culture conditions. GEM exhibits cytotoxicity against cultured PANC-1 cells with an $\mathrm{IC}_{50}$ value of $16 \mu \mathrm{g} / \mathrm{ml}(3)$.

Secretome purification. Conditioned medium was collected from the culture dishes and cooled on ice. Floating cells and cellular debris were removed by centrifugation $(2000 \mathrm{x} \mathrm{g}$, $10 \mathrm{~min}$ ) followed by sterile filtration (pore size, $0.22 \mu \mathrm{m}$ ) (5).

Proteins were concentrated by ultrafiltration using Centriplus YM-3 centrifugal filter devices according to the manufacturer's instructions. The total protein amount was determined using a standard Bradford protein assay.

2-DE and protein labeling with Cy dye. For 2-D gel electrophoresis with $\mathrm{Cy}$ dye, to $50 \mu \mathrm{g}$ protein in medium acetone (20-fold) was added and incubated at $-20^{\circ} \mathrm{C}$ for $2 \mathrm{~h}$. Then, acetone was removed by centrifugation $(7000 \mathrm{x} \mathrm{g}, 5 \mathrm{~min})$ and the precipitation was collected and dried in a SpeedVac (VC-15SP, Titec Co., Ltd., Saitama, Japan). The pellet was resuspended in $40 \mu \mathrm{l}$ isoelectric focusing (IEF) sample buffer [30 mM Tris-HCl, $8 \mathrm{M}$ urea, 4\% (w/v) 3-(3-chloamideopropyl)dimethylammonio)-1-propanesulfonic acid (CHAPS; $\mathrm{pH} 8.5)$ ]. Cy dye stock $(1 \mathrm{nMl} / \mu \mathrm{l})$ was diluted in anhydrous $\mathrm{DMF}$ (Sigma) to final concentration of $400 \mathrm{pM} / \mu 1$ and dye was added per $50 \mu \mathrm{g}$ protein. Two gels were used, control samples were labeled with $\mathrm{Cy} 3$ and samples from GEM treatment were labeled with Cy5 for 2 gels (6). Cy3 and Cy5 were used for the replacement samples for one gel. Protein $(25 \mu \mathrm{g})$ from control samples and GEM treatment samples were mixed and Cy2 was added to prepare the internal standard. The samples were vortexed, centrifuged for $10 \mathrm{sec}$, and incubated on ice for $30 \mathrm{~min}$ in the dark. The labeling reaction was terminated by adding $1.0 \mu \mathrm{l}$ L-lysine stock solution $(10 \mathrm{mM})$. Labeled proteins were mixed. Then, $330 \mu 1$ inhibition buffer [8 $\mathrm{M}$ urea, 2\% (w/v) CHAPS, $40 \mathrm{mM}$ dithiothreitol (DTT), $\mathrm{pH}$ 3.0-10.0, pharmalyte, $1 \%(\mathrm{w} / \mathrm{v})$ bromophenol blue] was added. We picked up the spot from another 2-D-gel to analyze nanoHPLC-ESI-MS/MS.

Precipitation was performed using 2-D DIGE technology (GE Healthcare). DIGE gels were scanned with Typhoon 9400 Variable Mode Imager (GE Healthcare). Excitation and emission wavelengths were chosen specifically, supernatants was separated by $2-\mathrm{D}$ polyacrylamide gel electrophoresis (PAGE) using immobilized $\mathrm{pH}$ gradient (IPG) strips. IPG gel with a linear gradient of $\mathrm{pH}$ 3.0-10.0 $(24 \mathrm{~cm})$ was used for IEF. The IPG gel was rehydrated for $10 \mathrm{~h}$ at $20^{\circ} \mathrm{C}$ using an IPGphor (GE Healthcare Bioscience). IEF at $20^{\circ} \mathrm{C}$ was programmed as follows: $1 \mathrm{~h}$ at $500 \mathrm{Vh}, 1 \mathrm{~h}$ at $800 \mathrm{Vh}, 3 \mathrm{~h}$ at $13.5 \mathrm{Vh}, 3.75 \mathrm{~h}$ at $20-30 \mathrm{Vh}$ (linear increase) (7). After IEF, the strips were incubated at room temperature for $30 \mathrm{~min}$ in a buffer consisting of $1.5 \mathrm{M}$ Tris- $\mathrm{HCl}$ ( $\mathrm{pH} 8.8$ ), $6 \mathrm{M}$ urea, 30\% (v/v) glycerol, $2 \%$ SDS, $16 \mathrm{mM}$ DTT, and $0.002 \%$ bromophenol blue (BPB) (6). Then, they were incubated in equilibration buffer containing $2.5 \mathrm{mg} / \mathrm{ml}$ iodoacetamide solution (other components were the same as in the solution containing DTT for $30 \mathrm{~min})(6)$. 
2-D SDS-PAGE on $10 \%$ running gel $(24 \times 20 \times 0.15 \mathrm{~cm})$ was performed as described below. The protocol for SDS-PAGE at $20^{\circ} \mathrm{C}$ was as follows: $20 \mathrm{~min}$ at $2.5 \mathrm{w} / \mathrm{w}$ gel, $3 \mathrm{~h}$ at $20 \mathrm{w} / \mathrm{w}$ gel. For each preparative gel, a total of $150 \mu \mathrm{g}$ protein labeled with $\mathrm{Cy}$ and $200 \mu \mathrm{g}$ non-labeled protein was loaded.

2-DE image analysis. DIGE gel image was scanned at $100 \mu \mathrm{m}$ resolution on Typhoon 9410 variable mode imager (GE Healthcare) using excitation/emission wavelengths specific for Cy2 (488/520 nm, blue laser), Cy3 (532/580 nm, green laser) and Cy5 (633/670 nm, red laser) (6). Laser power was chosen so that no saturated signal was obtained from any protein spot. Resolution was $100 \mu \mathrm{m}$. DIGE gels were analyzed using DeCyder 6.5 software (GE Healthcare) in batch processor mode with an estimated number of spots set to 2200 and the spot exclusion filter set to exclude any spot with a volume $<7500$. A batch processor was used to link the Differential In-gel Analysis (DIA) and Biological Variation Analysis (BVA) modules together in an automated fashion (7-11). The gel containing the highest number of spot features was designated the master gel, and manual spot matching was then performed to correctly match the remaining three Cy2 gel images and the Sypro Ruby stain master. In DIA, spot boundaries and volumes were co-detected for Cy3, Cy5, and $\mathrm{Cy} 2$ channels on each gel, and protein spot abundance was expressed as a standard:sample ratio. In BVA, protein abundance was compared across multiple samples using the internal standard to normalize between gels, and statistical analysis was performed to obtain the average ratio and one-way analysis of variance values between samples. The DIA module was used for pair wise comparisons of control and GEM treatment groups with the mixed standard present in each gel and for the calculation of normalized spot volume/ protein abundance.

Protein staining with SYPRO Ruby and Silver nitrate. For 2-D-gel electrophoresis and MS analysis, acetone (20-fold) was added to $200 \mu \mathrm{g}$ non labeled proteins in medium. After $2 \mathrm{~h}$ at $-20^{\circ} \mathrm{C}$, acetone was removed by centrifugation (7000 x g, $5 \mathrm{~min}$ ) and the precipitate was collected and dried in the SpeedVac. Two hundred micrograms of protein was loaded on on the gel. The gel was stained with SYPRO Ruby and spots of interest (downregulated spots) were picked with a spot picker (Ettan DIGE Sopt Picker, GE Healthcare). Another $200 \mu \mathrm{g}$ non-labelled protein on the gel was stained with Silver nitrate and spots of interest (upregulated spots) were picked manually.

In-gel tryptic digestion. To identify proteins, silver-stained and SYPRO Ruby-stained spots were excised from the gel. They were washed with a solution of $30 \mathrm{mM}$ potassium hexacyanoferrate (III) and $100 \mathrm{mM}$ sodium thiosulfate for $15 \mathrm{~min}$, then washed three times with water. Proteins in the gel were reduced with $10 \mathrm{mM}$ DTT/100 $\mathrm{mM} \mathrm{NH}_{4} \mathrm{HCO}_{3}\left(90 \mathrm{~min}, 56^{\circ} \mathrm{C}\right)$ and alkylated with $55 \mathrm{mM}$ iodoacetamide $/ 100 \mathrm{mM} \mathrm{NH}_{4} \mathrm{HCO}_{3}$ (45 min, in the dark at room temperature) (6). Gel spots were washed with acetonitrile and dried in a SpeedVac. Dried gel particles were rehydrated with digestion buffer containing $20 \mathrm{ng} / \mathrm{ml}$ sequencing grade trypsin in $100 \mathrm{mM} \mathrm{NH}_{4} \mathrm{HCO}_{3}$ at $0^{\circ} \mathrm{C}$ for $30 \mathrm{~min}$. Then they were incubated at $37.7^{\circ} \mathrm{C}$ over- night (6). After digestion, peptides were first extracted from gel pieces with 50\% ACN/0.1\% tetra fluoroacetic acid (TFA) (50:50), followed by second extracted from gel pieces with $75 \%$ ACN/0.1\% TFA (75:25).

The two extracts were pooled and concentrated in a SpeedVac, and $0.5 \%$ TFA was added to approximate $20 \mu 1$ of the concentrated solution. Desalting was performed using ZipiTip $\mu \mathrm{C} 18$ (Millipore, Bedford, MA) following the manufacturer's instructions.

Identification by mass spectrometry. Tryptic peptides were analyzed by nano-HPLC-ESI-TOF-MS/MS using a nano Frontier LD (Hitachi High Technologies, Ltd.). Peptide identifications were performed using the Mascot search engine. Within the ProteinScape database, protein search was initiated using Mascot search algorithms. Proteins were identified by searching against a human subset of the Swiss-Prot protein database using the Mascot 2.1.0 search algorithm. The following search parameters were selected: up to one missed cleavage site in case of in complete trypsin hydrolysis was allowed and data were searched using carbamidation and oxidation as variable modifications. The peptide mass tolerance was set at $0.5 \mathrm{Da}$ for monoisotopic masses and $0.6 \mathrm{Da}$ for fragment masses. All searches were run in the mammalian protein subdatabase of Swiss-Prot database to exclude putative contamination of bovine serum proteins originating from the culture medium.

Similarly, tryptic peptides were analyzed by another nano-HPLC-ESI-TOF-MS/MS using Agilent 6500 (Agilent Technologies, Ltd.). Peptide identifications were performed using the Mascot search engine (data not shown).

Western blot analysis. Protein concentrations were determined by the Bradford assay using bovine serum albumin as a standard (Protein Assay kit, Bio-Rad Laboratories). Total protein extracts $(50 \mu \mathrm{g})$ were mixed with SDS sample buffer (6.25 mM Tris-HCl, pH 6.8, 2.3\% SDS, $10 \%$ glycerol, $5 \% \beta$-mercaptoethanol, $0.005 \%$ bromophenol blue) and resolved by SDS-PAGE on 10-20\% gradient acrylamide gels (8). Proteins $(50 \mu \mathrm{g})$ were detected immunologically following semidry electrotransfer (Trans-Blot SD semi-dry electrotransfer system, Bio-Rad Lboratories) onto PVDF membranes (Millipore). The membranes were blocked with 5\% non-fat dry milk in Tris-buffered saline with Tween-100 for $30 \mathrm{~min}$ at room temperature and incubated for $2 \mathrm{~h}$ at room temperature with the following primary antibodies: anti-14-3-3 o (1:1000, Abcam, rabbit monoclonal antibody), and anti-LF (1:5000, Abcam, rabbit monoclonal antibody). After washing three times in $0.5 \%$ non-fat dry milk in Tris-buffered saline with Tween-100, blots were incubated with horseradish peroxidase-conjugeated secondary antibody (diluted 1:5000, Abcam) for $2 \mathrm{~h}$ at room temperature. Immunoreactive complexes were visualized using HRP-DAB detection kit (Wako). Bands were measured and calculated using LAS-4000 (Fujifilm).

$S D S-P A G E$. Proteins in control and GEM treated smples $(50 \mu \mathrm{g})$ were analyzed by SDS-PAGE. We performed SDS-PAGE in the presence of 2-mercaptoethanol using slab gels in a Tris/glycine buffer system ( $\mathrm{pH} \mathrm{8.3),} \mathrm{as} \mathrm{described}$ 


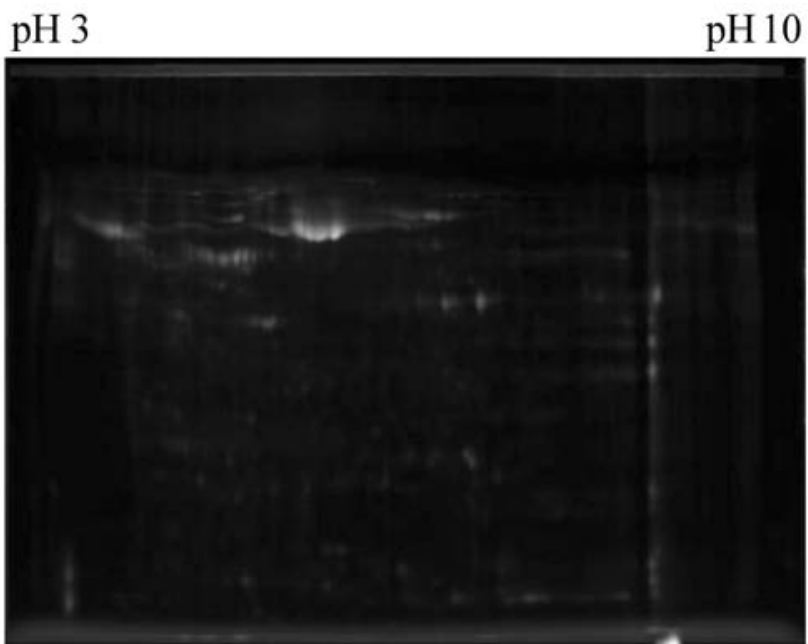

Figure 1. Typical DIGE gel for conditioned medium (CM). Match of all fluorescent Cy spots.

by Schagger and von Jagow (12). The gel was stained with Coomassie Brilliant Blue.

\section{Results}

Control media and GEM treated media were filtered and concentrated. Proteins in control media and GEM treated media were differentially labeled and analyzed by 2-D DIGE. Three replica gels were considered for the quantitative and statistical analysis using the DeCyder ${ }^{\mathrm{TM}} 6.5$ software. This analysis revealed changes in the abundance of 53 spots. Twenty-two spots were significantly upregulated (average. GEM treatment/control ratio $>1.2, P \leq 0.01$ ), whereas 31 were downregulated (average GEM treatment/control ratio $<0.66$, $\mathrm{P} \leq 0.01$ ). Fig. 1 shows a representative 2-D gel image. Arrows indicate proteins identified whose expression was within the 99th confidence level.

For MS analysis, each $200 \mu \mathrm{g}$ of non-labeled protein in the medium was subjected to 2-D gel electrophoresis. One gel was stained with silver nitrate and another with SYPRO Ruby. Twenty-two upregulated spots were picked from the gel stained with silver (Fig. 2A, the data of 22 spots are not shown), and 31 downregulated spots were picked from the gel stained with SYPRO Ruby (Fig. 2B, the data of 31 spots are not shown). After in-gel tryptic digestion, protein identifications were combined using the Mascot search engine against the Swiss-Prot database to yield a set of 'mammalian' protein identifications with confidence values. Proteins identified as bovine or from another mammalian were removed because of the possibility of contamination from bovine serum albumin. As a result, 37 upregulated and 30 downregulated 'human proteins' were identified (data not shown). The subcellular locations of most identified proteins were the cytoplasm, nucleus and membrane. Secreted proteins among the upregulated proteins comprised 14-3-3 $\sigma$, protein S100-A8, protein S100-A9 and galectin-7. Secreted proteins among the downregulated proteins comprised LF precursor, TF precursor, and vitamin D binding protein precursor (Table I).
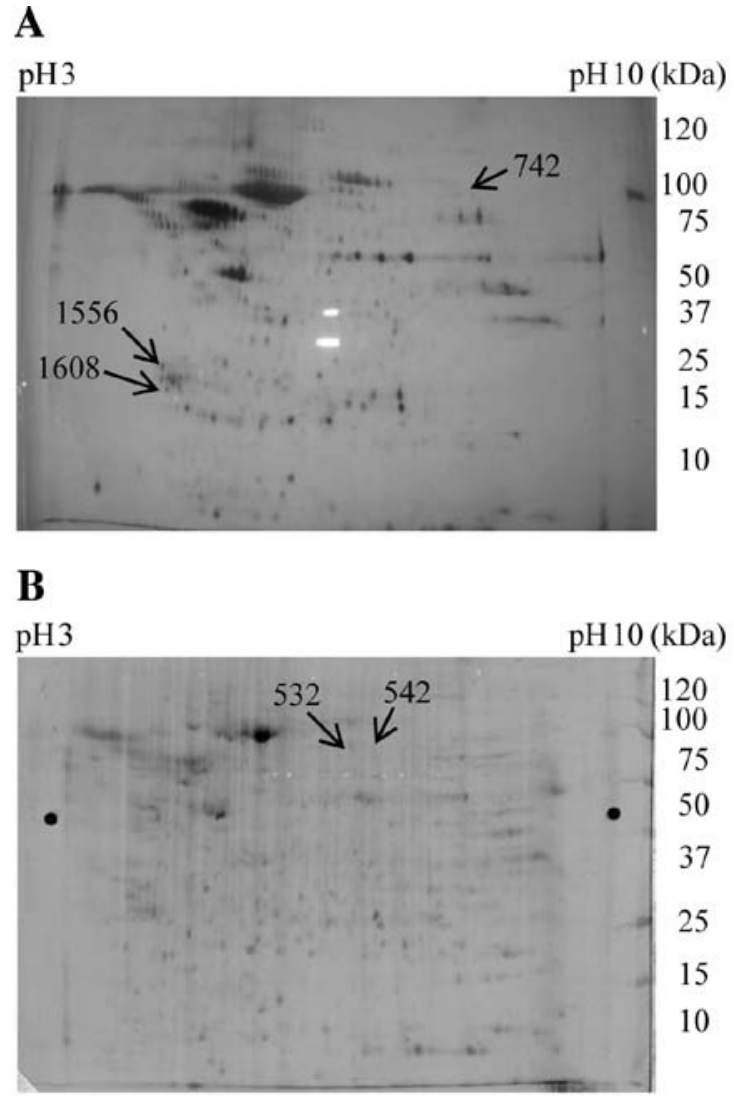

Figure 2. Typical DIGE gel of conditioned medium. (A) The gel was silver stained. Upregulated spots $(742,1552$ and 1608) were marked with an arrow on the silver stained gel.(B) The gel was stained with SYPRO Ruby. Downregulated spots (532 and 542) were marked with arrows on the stained gel.

LF precursor consisted of 710 amino acids and produced six proteins or peptides by molecular processing (http:// www.uniprot.org/uniprot/P02788) (Table II). The regions of LF precursor identified by nano-HPLC-ESI-TOF-MS/ MS were amino acids 191-199, 316-320, 321-328, 424-435 and 542-552 (Table I). We could not identify the true protein using MS/MS data alone. However, the spots on 2-DE gel indicated that the molecular weight was $\sim 60-80 \mathrm{kDa}$ and the pI 8-9 (Fig. 2B).

To validate 14-3-3 $\sigma$ and LF, we performed western blot analysis to determine the levels of these proteins in control and GEM treated media. In treated medium 14-3-3 $\sigma$ was upregulated (Fig. 3), but LF was downregulated (Fig. 4). The GEM treatment/control ratios for 14-3-3 $\sigma$ and LF precursor were 2.87 and 0.38 , respectively (Table I). These data were consistent with the data of western blotting.

When validation of proteins in lysate was performed, we used $\beta$-actin or G3PDH for the reference. However, in the present study proteins in the control and treatment samples were analyzed by SDS-PAGE. The gel was stained with Coomassie Brilliant Blue (Fig. 5).

\section{Discussion}

The mechanism of the anticancer effect of GEM is the inhibition of DNA synthesis. However, information regarding other such events is limited. A transcriptome approach revealed 


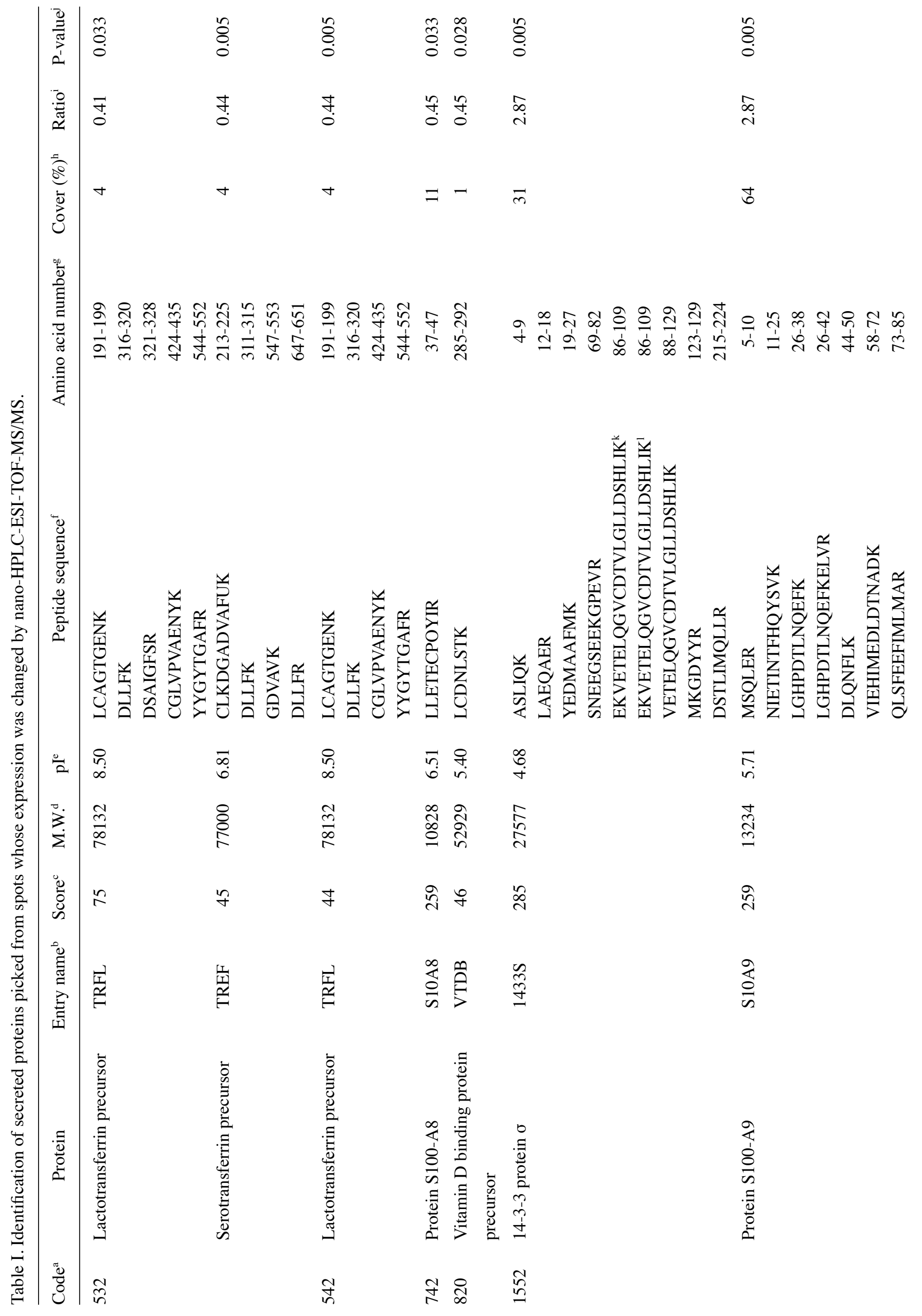


Table II. Moleculare processing of lactotransferrin (LF) precursor.

\begin{tabular}{lcc}
\hline Name & Sequence & No. of amino acid \\
\hline No name & $1-19$ & 19 \\
Lactotransferrin & $20-710$ & 691 \\
Kaliocin-1 & $171-101$ & 31 \\
Lactoferroxin & $338-34$ & 6 \\
Lactoferroxin & $543-547$ & 5 \\
Lactoferroxin & $680-686$ & 7 \\
\hline
\end{tabular}

LF precursor produced six peptides or proteins.

A

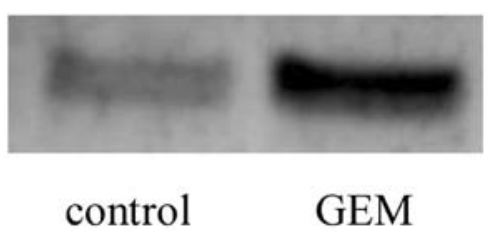

B

(\%)

200

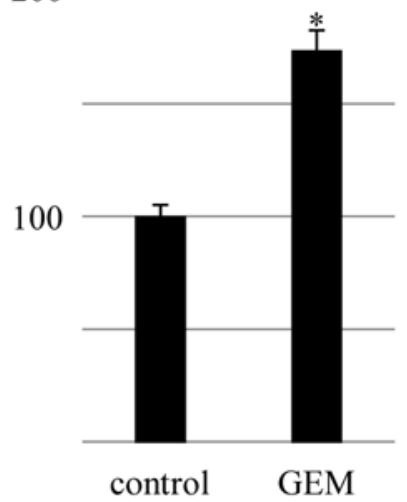

Figure 3. Validation of 14-3-3 $\sigma$ by western blotting. Fifty micrograms of proteins was applied to the gel. The proteins was transferred to PVDF. Expression of 14-3-3 $\sigma$ in conditioned medium treated with GEM was upregulated compared with control. (A) Pair of bands from control and GEM treatment. (B) Graph based on the area $(n=3)$. ${ }^{*} \mathrm{P}<0.05$.

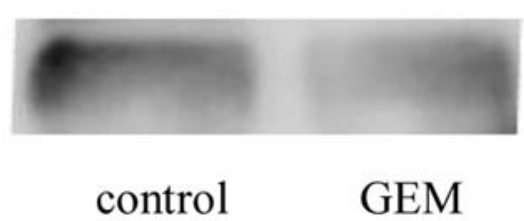

Figure 4. Validation of LF by western blotting. Fifty micrograms of protein was applied to the gel. The expression of LF in control conditioned medium was downregulated compared with GEM treatment medium $(n=3)$.

upregulation of 53BP1 mRNA in PANC-1 cells treated with GEM (3). However, use of proteomics in pancreatic cell lines treated with GEM has not been reported. We therefore used 


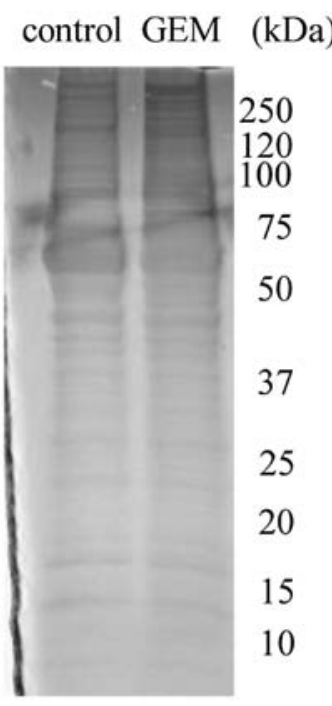

Figure 5. SDS-PAGE analysis of CM. Fifty micrograms of protein was applied to the gel, and the gel was stained with Coomassie Brilliant Blue $(n=3)$. In the regions of $60-8$ and $20-30 \mathrm{kDa}$, control and treatment samples were of equal quantity.

secretome analysis to investigate the response of PANC-1 cells treated with GEM. In recent years, studies on secretome have seen rapid acceleration as a result of technological advances, particulary in proteomics.

A method for secretome analysis has been established (5). Carcinoma cells or primary cells were maintained in medium with FBS and incubated for growth. Then, the cells were washed with PBS or serum-free medium (SFM) and incubated in SFM for an appropriate time to remove FBS. Conditioned medium was collected, centrifuged, and subjected to sterile filtration to remove floating cells and cellular debris. Supernatant was collected and concentrated.

Proteins in conditioned medium were thought to be secreted proteins or exported proteins from the cell lines. However, in addition to secreted proteins, the proteins collected from conditioned medium include, cytoskeletal components, membrane components, and nucleus proteins $(13,14)$. This problem cannot be avoided because of cell death. In this study, we targeted secreted protein in the Swiss-Prot database (http://expasy.org/sprot/). However, we were confronted with another difficult problem. In the proteomics analysis of serum, plasma, urine, and organs obtained from humans, protein identifications were combined using a software search engine to yield a set of 'human' protein identifications with confidence values. In proteome analysis of human cell lines in vitro (15-21), many investigators selected the taxonomic term 'human' when using the software search engine to yield a set of protein identifications. However, proteins may be contaminated by bovine proteins originating from FCS (22).

We selected the taxonomic term 'mammalian' when using the Mascot search engine to yield a set of protein identifications to exclude bovine proteins. Data from 2-DE and MS screening indicated upregulation of four secreted proteins and downregulation of three secreted proteins in PANC-1 cells treated with GEM. Protein S100-A8, identified from spot
742 , might be a pseudo-positive protein because of its high molecular weight and a pI 9-10 (Fig. 2A, Table I).

We confirmed the existence of 14-3-3 $\sigma$ and LF and the upregulation and downregulation of these protein.

14-3-3 $\sigma$ belongs to the 14-3-3 protein family (23-25), which is a class of highly conserved proteins involved in regulating signal transduction pathways, apoptosis, adhesion, cellular proliferation, differentiation and survival. Among all 14-3-3 proteins, 14-3-3 $\sigma$ is the isoform most directly linked to cancer. There are several lines of evidence indicating that 14-3-3 $\sigma$ acts as a tumor suppressor gene and that its inactivation is crucial in tumorigenesis $(26,27)$. In primary culture of the conjunctival epithelial cell line $\mathrm{Cj}$-ECs, nerve growth factor induced 14-3-3 $\sigma$ mRNA and protein (28).

Protein 14-3-3 $\sigma$ is known to be locatd in the cytoplasm and nucleus. Beacuse 14-3-3 $\sigma$ does not harbor any typical aminoterminal ER export signal, the route of its externalization remains to be determined. However, 14-3-3 $\sigma$ may be secreted by a non-classial secretory pathway (29). Recombinant 14-3-3 $\sigma$ was found to sufficiently induce matrix metallolloproteinase 1 (MMP1) expression in fibroblasts (30). It seems possible that GEM induces secretion of 14-3-3 $\sigma$. Secreted 14-3-3 $\sigma$ may act on the cell surface or stimulate cells to suppress tumorigenesis. Altenatively, secreted 14-3-3 $\sigma$ may be associated with undesirable side effects of GEM.

LF is a member of the transferrin family of iron-binding proteins. It was originally isolated from human milk (31). LF has been detected in many biological fluids as well as in human fetal and adult tissue by radioimmunologic and immunoenzymatic procedures, LF has been detected in many biological fluids as well as in human fetal and adult tissue (32-37). Immunohistochemistry has been used to study the distribution of LF in normal human tissues, such as stomach, kidney, lung, pancreas, liver and bone marrow (34). LF immunoreactivity has been extensively investigated in human neoplastic conditions (38-50). LF inhibited carcinogenesis and metastasis of malignant tumors in mice (51) and in the human pancreatic cell line SPA (52).

If GEM inhibits the secretion or production of LF to promote metastasis, this would be an undesirable side effect.

\section{References}

1. Haugk B: Pancreatic intraepithelial neoplasia - can we detect early pancreatic cancer? Histopahology 57: 503-514, 2010.

2. Tanaka M, Javel M, Dong X and Eng C, Abbruzzese JL and Li D: Gemcitabine metabolic and transporter gene polymorphisms are associated with drug toxicity and efficacy in patients with locally advanced pancreatic cancer. Cancer 116: 5325-5335, 2010

3. Shimasaki T, Ishigaki $\mathrm{Y}$, Minamoto $\mathrm{T}$ and Motoo R: The influence of expression of Apopthosis related genes in pancreatic cell lines treated with gemcitabine hydrochrolide. Suizo 22: 14-20, 2007.

4. Wallentine JC, Kim KK, Seiler CE III, Vaughn CP, Crockett DK, Tripp SR, Elenitoba-Johnson KS and Lim MS: Comprehensive identification of proteins in Hodgkin lymphoma-derived Reed-Sternberg cells by LC-MS/MS. Lab Invest 87: 1113-1124, 2007.

5. Xue H, Lu B and Lai M: The cancer secretome: a reservoir of biomarkers. J Trans Med 6: 1-12, 2008.

6. Soares JCS, Santos MF, Trrugilho MRO, Neves-Ferreira AGG, Perales J and Domont GB: Differential proteomics of the plasma of individuals with sepsis caused by Acinetobacter bumannii. J Proteomics 73: 267-278, 2009. 
7. Mares J, Thongboonkerd V, Tuma Z, Moravec J, Karvunidis T and Matejovic M: Proteomic analysis of proteins bound to adsorption units of extracorporeal liver support system under clinical conditions. J Proteome Res 8: 1756-1764, 2008.

8. Sun Q, Sha H, Yang X, Bao G, Lu J and Xie Y: Comparative proteomic analysis of paclitaxel sensitive A549 lung adenocarcinoma cell line and its resistant counterpart A549-Taxol. J Cancer Res Clin Oncol 137: 521-532, 2010.

9. Shi J, Zen Y and Zheng R: Proteome profiling of early seed development in Cunninghamia lanceolata (Lamb.) Hook. J Exp Bot 61: 2367-2381, 2010.

10. Oshita F, Morita A, Ito H, Kameda Y, Tsuchiya E, Shigeru A and Miyagi Y: Proteomic screening of completely resected tumors in relation to survival in patients with stage I non-small cell lung cancer. Oncol Rep 24: 637-645, 2010.

11. Varo I, Rigos G, Navarro JC, del Ramo J, Giner C, Hernandez A, Pertusa J and Torreblanca A: Effect of ivermectin on the liver of gilthead sea bream Sparus aurata: a proteomic approach Chemosphere 80: 570-577, 2010.

12. Schagger H and von Jagow W: Tricine-sodium dodecyl sulfatepolyacrylamide gel electrophoresis for the separation of proteins in the range from 1 to $100 \mathrm{kDa}$. Anal Biochem 166: 368-379, 1987.

13. Chillini C, Cochet O, Negroni L, Samson M, Poggi M, Ailhaud G, Alessi MC, Dani C and Amri EZ: Characterization of human mesenchymal stem cell secretome at early steps of adipocyte and osteoblast differentiation. BMC Mol Biol 9: 1-16, 2008.

14. Hathout Y: Approaches to the study of the cell secretome. Expert Rev Proteomics 4: 239-248, 2007.

15. Gronborg M, Kristiansen TZ, Iwahori A, Chang R, Reddy R, Sato N, Molina H, Jensen ON, Hruban RH, Goggins MG, et al: Biomarker discovery from pancreatic cancer secretome using a differential proteomic approach. Mol Cell Proteomics 5: 157-171, 2006.

16. Keshamouni VG, Michailidis G, Grasso CS, Anthwal S, Strahler JR, Walker A, Arenbrg DA, Reddy RC, Akulapalli S, Thannickal VJ, et al: Differential protein expression profiling by iTRAQ-2DLC-MS/MS of lung cancer cells undergoing epithelial-mesenchymal transition reveals a migratory/invasive phenotype. J Proteome Res 5: 1143-1154, 2006.

17. Yamashita R, Fujikawa Y, Ikari K, Hamada K, Otomo A Yasuda K, Noda M and kaburagi Y: Extracellular proteome of human hepatoma cell, HepG2 analyzed using two-dimensional liquid chromatography coupled with tandem mass spectrometry. Mol Cell Biochem 298: 83-92, 2007.

18. Wu CC, Chen HC, Chen SJ, Liu HP, Hsieh YY, Yu CJ, Tang R, Hsieh LL, Yu JS and Chang YS: Identification of collapsin response mediator protein-2 as a potential marker of colorectal carcinoma by comparative analysis of cancer cell secretomes. Proteomics 8: 316-332, 2007.

19. Ma Y, Visser L, Roelofsen H, de Vries M, Diepstra A, van Imhoff G, van der Wal T, Luinge M, Alvarez-Llamas G, Vos $\mathrm{H}$, et al: Proteomics analysis of Hodgkin lymphoma: identification of new players involved in the cross-talk between HRS cells and infiltrating lymphocytes. Blood 111: 2339-2346, 2008

20. Butler GS, Dean RA, Etam EM and Overall CM: Pharmacoproteomics of a metalloproteinase hydroxamate inhibitor in breast cancer cells: dynamics of membrane type 1 matrix metalloproteinase-mediated membrane protein shedding. Mol Cell Biol 28: 4896-4914, 2008.

21. Sarkissian G, Ferglot P, Lamy PJ, Petard JJ, Culine S, Jouin P Rioux-Leclercq N and Darbouret B: Identification of pro-MMP-7 as a serum marker for renal cell carcinoma by use of proteomic analysis. Clin Chem 54: 574-581, 2008.

22. Tunica DG, Yin X, Sidibe A, Stegemann C, Nissum M, Zeng L, Brunet M and May M: Proteomic analysis of the secretome of human umbilical vein endothelial cells using a combination of free-flow electrophoresis and nanoflow LC-MS/MS. Proteomics 9: 4991-4996, 2009.

23. Mohammad DH and Yaffe MB: 14-3-3 proteins, FHA domains and BRCT domains in the DNA damage response. DNA Repair 8: 1009-1017, 2009

24. Morrison DK: The 14-3-3 proteins: integrators of diverse signaling cues that impact cell fate and cancer development. Trens Cell Biol 19: 16-23, 2009.

25. Obsilova V, Sihan J, Boura E, Teisinger J and Obsil T: 14-3-3 proteins: a family of versatile molecular regulators. Physiol Res 57 (Suppl 3): S11-S21, 2008.
26. Ferl RJ, Manak MS and Reyes MF: The 14-3-3 $\sigma$ reviews. Genome Biol 3: 30101-30107, 2002.

27. Yang $H$, Wen $Y$, Chen $C$, Loxano $G$ and Lee M: 14-3-3 sigma positively regulates 553 and suppresses tumor growth. Mol Cell Biol 23: 7096-7107, 2003.

28. Lambiase A, Micera A, Pellegrini G, Merlo D, Rama P, Luca MD and Bonini S: In vitro evidence of nerve growth factor effects on human conjunctival epithelial cell differentiation and mucin gene expression. Invest Ophthalmol Vis Sci 50 4622-4630, 2009.

29. Hermerking H: Extracellular 14-3-3 sigma protein: a potential mediator of epithelial-mesenchymal interactions. J Invest Dermatol 124: 9-10, 2005.

30. Ghahary A, Marcoux Y, Karimi-Busheri F, Li Y, Tredget EE, Kilani RT, Lam E and Weinfeld M: Differentiated keratinocyte-releasable stratifin (14-3-3 sigma) stimulates MMP-1 expression in dermal fibroblasts. J Invest Derrmatol 122: 1188-1197, 2004.

31. Steijns JM and van Hooijdonk AC: Occurrence, structure, biochemical properties and technological characteristics of lactoferrin. Br J Nutr 84: 11-17, 2000.

32. Masson PL, Heremans JF and Dire CH: Lactoferrin, an ironbinding protein in neutrophilic leukocytes. Clin Chim Acta 14: 735-739, 1996.

33. De Vet BJCM and van Gool J: Lactoferrin and iron absorption in the small intestine. Acta Med Scand 196: 393-402, 1974.

34. Mason DY and Taylor CR: Distribution of transferrin, ferritin and lactotranseferrin human tissues. J Clin Pathol 31: 316-327, 1978.

35. Brock J: Lactoferrin in human milk: its role in iron absorption and protection against enteric infection in the newborn infant. Arch Dis Child 55: 417-421, 1980.

36. Reitamo S, Konttinen YT and Segerberg-Konttinen M: Distribution of lactoferrin in human salivary glands. Histochemistry 66: 285-291, 1980.

37. Korsud FR and Brandtzaeg P: Characterization of epithelial elements in human major salivary gland by functional markers: localization of amylase, lactoferrin, lysozyme, secretory component, and secretory immunoglobulins by paired immunofluorescence staining. J Histochem Cytochem 30: 657-666, 1982.

38. Caselitz J, Jaup T and Seifert G: Lactoferrin and lysozyme in carcinomas of the parotid gland. A comparative immunocytochemical study with the occurrence in normal and inflamed tissue. Virchows Arch A Pathol Anat Histol 394: 61-73, 1981

39. Barresi G and Tuccari G: Lactoferrin in benign hypertrophy and carcinomas of the prostatic gland. Virchows Arch A Pathol Anat Histopathol 403: 59-66, 1984.

40. Rossiello R, Carriero MV and Giordano GG: Distribution of ferritin, transferrin and lactoferrin in breast carcinoma tissue. J Clin Pathol 37: 51-55, 1984

41. Charpin C, Lachard A, Pourreau SN, Jacquemier J, Lvaut MN, Andonian C, Martin PM and Toga M: Localization of lactoferrin and nonspecific cross-reacting antigen in human breast carcinomas. An immunohistochemical study using the avidin-biotin-peroxidase complex method. Cancer 55: 2612-2617, 1984.

42. Tuccari G and Barresi G: Immunohistochemical demonstration of lactoferrin in follicular adenomas and thyroid carcinomas. Virchows Arch A Pathol Anat Histopathol 406: 67-74, 1985.

43. Baressi G and Tuccari G: Iron-binding proteins in thyroid tumours. An immunocytochemical study. Pathol Res Pract 182: 344-351, 1987.

44. Louglin KR, Gittes RF and Patridge D: The relationship of lactoferrin to the anemia of renal carcinoma. Cancer 59: 566-571, 1987.

45. Tuccari G, Barresi G, Arena F and Inferrera C: Immunocytochemical detection of lactoferrin in human gastric carcinomas and adenomas. Arch Pathol Lab Med 113: 912-916, 1989.

46. Carbaret V, Vilain MO, Delobelle-Deroide $A$ and Vanseymortier L: Immunohistochemical demonstration of ceruloplasmin and lactoferrin in a series of 59 thyroid tumors. Ann Pathol 12: 347-352, 1992 (In French).

47. Tuccari G, Rizzo A, Crisafulli $\mathrm{C}$ and Barresi G: Iron-binding proteins in human colorectal adenomas and carcinomas: an immunocytochemical investigation. Histol Histopathol 7: 543-547, 1992.

48. Yossie Asato de Camargo R, Longatto Filho A, Alves VA, Bisi H, Kanamura CT and Alves Abelin NM: Lactoferrin in thyroid lesions: immunoreactivity in fine needle aspiration biopsy samples. Acta Cytol 40: 408-413, 1996. 
49. Tuccari G, Rossiello R and Barresi G: Iron binding proteins in gallbladder carcinomas. An immunocytochemical investigation. Histol Histopathol 12: 671-676, 1997.

50. Tucarri G, Giffre G, Crisafulli C and Barresi G: Immnohistochemical detection of lactoferrin in human astrocytomas and multiforme glioblastomas. Eur J Histochem 43: 317-322, 1999.
51. Bezault J, Bhimani R, Wiprovnick J and Fumanski P: Human lactoferrin inhibits growth of solid tumors and development of experimental metastases in mice. Cancer Res 54: 2310-2312, 1994.

52. Sakamoto N: Antitumor effect of human lactoferrin against newly established human pancreatic cancer cell line SPA. Gan To Kagaku Ryoho 25: 1557-1563, 1998 (In Japanese). 